Aquaculture

March 2017, Volume 470, Pages 40-49

http://dx.doi.org/10.1016/j.aquaculture.2016.12.014

http://archimer.ifremer.fr/doc/00361/47217/

(c) 2016 Elsevier B.V. All rights reserved.

\title{
Investigation of morphological predictors of fillet and carcass yield in European sea bass (Dicentrarchus labrax) for application in selective breeding
}

\author{
Vandeputte Marc ${ }^{1,2,{ }^{*} \text {, Puledda Antonio }}{ }^{3,4}$, Tyran Anne Sophie ${ }^{5}$, Bestin Anastasia ${ }^{5}$, \\ Coulombet Céline ${ }^{6}$, Bajek Aline ${ }^{1,2}$, Baldit Gwénaëlle ${ }^{2}$, Vergnet Alain ${ }^{3}$, Allal Francois, \\ Bugeon Jérôme ${ }^{7}$, Haffray Pierrick ${ }^{5}$
}

${ }^{1}$ GABI, INRA, AgroParisTech, Université Paris-Saclay, F-78350 Jouy-en-Josas, France

2 Ifremer, Chemin de Maguelone, F-34250 Palavas-les-Flots, France

3 Ifremer, UMR9190 MARBEC, Chemin de Maguelone, F-34250, Palavas-les-Flots, France

${ }^{4}$ Section of Animal Science, Department of Agriculture, University of Sassari, Sassari, Italy

${ }^{5}$ SYSAAF Section Aquacole, Campus de Beaulieu, F-35000 Rennes, France

${ }^{6}$ Ecloserie Marine de Gravelines-Ichtus, Voie des Enrochements, F-59820 Gravelines, France

${ }^{7}$ LPGP, INRA, F-35000 Rennes, France

*Corresponding author : Marc Vandeputte, email address : marc.vandeputte@jouy.inra.fr

\begin{abstract}
:
Genetic parameters for carcass and fillet percentage were estimated in 760 European sea bass reared under commercial conditions and slaughtered at 573 days post fertilization (395 g mean body weight). Phenotyped fish were the offspring of 45 sires and 20 dams crossed in a factorial mating design. Pedigrees were re-constructed with $90.7 \%$ success using 12 microsatellites. The heritability of fillet yield was moderately low $(0.21)$, while it was high for carcass yield $(0.57)$. Both traits were poorly correlated (- 0.01 to 0.28$)$ making space for their combined improvement. We investigated different predictors derived from measurement of surfaces on digital pictures and ultrasound measurements at several points of the body. The accuracy of the phenotypic prediction was rather low for fillet yield $(r 2=0.02-$ $0.18)$, but higher for carcass yield $(r 2=0.27-0.41)$. However, genetic correlations of predictors with the traits to predict were reasonably high (up to 0.67 for fillet yield and 0.95 for carcass yield), thus allowing to consider them for performing indirect individual selection instead of sib selection. However, it was difficult to design a predictor that would simultaneously increase fillet yield and carcass yield because of contradicting effects of relative head size, an important component of the predictors which was positively correlated to carcass yield but not to fillet yield.
\end{abstract}

Statement of relevance We estimated phenotypic predictors for processing yields in the European sea basslane estimated their genetic variation and correlations with the traits to predict. This is important to be able to apply indirect selection for processing yields in this species. This showed that although the traits of interest were hardly correlated, it was not possible to find external predictors having a significant positive impacts on both traits (carcass and fillet yield) simultaneously. This highlights the need to study specifically these issues in different species and conditions, as the picture here is very different to the well studied case of rainbow trout for example. 


\section{Highlights}

- We investigated morphological predictors and heritability of fillet and carcass yields in European sea bass. Fillet and carcass yield were heritable, but uncorrelated. It was not possible to find unequivocal morphological predictors applicable to both fillet and carcass.

Keywords : Ultrasound tomography, Genetics, Heritability, Indirect selection, Processing yields 


\section{Introduction}

European sea bass (Dicentrarchus labrax) one of the most important species reared in the Mediterranean since the 1980's (Chatain and Chavanne, 2009). In the wild, sea bass is widely distributed in the Mediterranean, the Black Sea and the Eastern coast of the Atlantic Ocean (from Norway to Morocco). The global production of European sea bass accounted for 161,059 tons in 2013 (FAO, 2016). Aquaculture is the agricultural sector with the highest rate of growth and as any other growing industry, the optimisation of production is becoming a necessity, genetic improvement being a major way to optimize productivity. Several previous studies on the genetics of sea bass have focused on the improvement of traits such as growth rate (Dupont-Nivet et al., 2008, 2010; Saillant et al., 2006; Vandeputte et al., 2009), body composition and processing traits (Gorshkov et al., 2004; Haffray et al., 2007; Saillant et al., 2009), survival and control of sex (Saillant et al., 2002; Vandeputte et al., 2007) and deformities (Bardon et al., 2009; Karahan et al., 2013). Quantitative genetic variation was evidenced for most of the traits investigated. In addition to those, new traits such as carcass quality, processing efficiency (improvement of the edible fraction) and impact of production (environmental footprint) are becoming interesting for aquaculture. Texture, colour, abdominal and flesh fat content are qualitative traits able to influence the final products and consumer preferences (García-Celdrán et al., 2015; Neira et al., 2004;). Processing traits are more interesting for fish producers, directly influencing their profitability (Saillant et al., 2009). An important processing trait, the fillet percentage, may raise attention of both producers, consumers and citizens. A higher fillet percentage involves a higher production of edible portions, a more favourable global feed conversion (amount of feed needed to produce a given amount of edible flesh - provided fish with higher fillet yield do not have a lower feed conversion ratio), the reduction of processing waste and an improvement of the ecological efficiency when the functional unit considered is the quantity of edible flesh and not the quantity of round fish produced (Acosta-Alba et al., 2015). As happened in France for rainbow trout (Oncorhynchus mykiss), where consumer demand for fresh and smoked fillet induced the increase of slaughtering weight from 0.3 to $3.5 \mathrm{~kg}$ (Bisault, 2009) and a change towards a salmon-like elongated shape (Haffray et al., 2013), the increase of harvest weight is getting into practice for European sea bass. In 2005, 20\% of the sea bass production was already constituted by fish bigger than $0.8 \mathrm{~kg}$ (Chatain and Chavanne, 2009). From the genetic point of view, the introduction in the selection index of traits correlated with fillet percentage, easier to score and more heritable (e.g. 
headless gutted carcass percentage - Haffray et al., 2012) as well as the adoption of individual scoring of candidates through indirect and non-lethal selection criteria have been shown to be relevant to increase fillet percentage in the French trout breeding industry (Haffray et al., 2013). Exploiting the within family variability, individual selection based on indirect criteria is potentially more efficient than the traditional sib selection, due to the possibility to obtain higher selection intensities.

In the last decades, estimates for production and processing traits (growth and carcass) were produced for Mediterranean fish species, in particular for Gilthead sea bream (Sparus aurata) (García-Celdrán et al., 2015; Navarro et al., 2009) and European sea bass (Bestin et al., 2014; Haffray et al., 2007; Saillant et al., 2009), but in the latter species without reporting indirect selection traits that can be measured on live breeding candidates. However, processing yields are clearly declared as breeding objectives in some European seabass selective breeding programmes (Chavanne et al., 2016).

The aim of this study was to provide estimates of genetic parameters for body and carcass traits in a population of European sea bass reared under commercial conditions, to determine morphological indicators able to predict processing yields (indirect criteria) and to predict the genetic progress achievable with their application in a hypothetical selection scheme. 


\section{Materials and methods}

\section{Production and rearing of families}

An expected total of 329 families of European sea bass were produced in September 2012 at the "Ecloserie Marine de Gravelines” (EMG) breeding station through artificial fertilization of gametes deriving from 47 sires and 21 dams crossed in two 16 sires $x 7$ dams and one 15 sires $x 7$ dams full factorial mating plans. The parents were broodstock from EMG's ongoing fifth generation of sea bass breeding program. Each individual spawn was separated in 15 or 16 aliquots, each aliquot being fertilized by the sperm from one sire. After fertilization, all aliquots from each of the 21 dams were grouped by dam and incubated in an individual jar. After $24 \mathrm{~h}$, a $45 \mathrm{~g}$ aliquot of live (floating) eggs was collected from each of the 21 jars, and all aliquots were pooled to obtain a single batch containing an equal quantity of eggs from each of the dams. All fish were kept as one group in common garden until April 2014 when they reached an average fork length of $31.5 \mathrm{~cm}$ and an average body weight of $395 \mathrm{~g}$.

\section{Slaughter chain and processing data collection.}

The fish traits measurements and the rearing environments were indexed according to the ATOL (Animal Trait Ontology for Livestock) ontology, available on the ATOL (http://www.atolontology.com/index.php/en/les-ontologies-en/visualisation-en) website (Golik et al., 2012, Le Bail et al., 2014).

At 573 days post fertilization (April 2014), 1002 sea bass were randomly sampled from a total of 2000 fishes. Fishes were first lightly anaesthetized in the tank $(0.1 \mathrm{ml} / 1$ phenoxyethanol $)$, then separated in groups of 5-6 individuals and killed with a lethal dose of phenoxyethanol $(0.5 \mathrm{ml} / \mathrm{l})$. This terminal anaesthesia delays the effects of rigor mortis that might compromise the quality of digital photos and the filleting operation. Every fish was photographed (Canon EOS 1000D) with the dorsal fin deployed in order to distinctly show all morphometric landmarks (Fig. 1). A sample of caudal fin was then cut and stored in ethanol for later DNA extraction and parentage assignment. For each fish, fork length was recorded to the nearest $0.1 \mathrm{~mm}$ with an in-house electronic ruler, total body weight was measured to the nearest $0.5 \mathrm{~g}$, and 10 ultrasound measurements were collected using an ultrasound scanner (see below). After biometry, each fish was portioned into the following body compartments: left fillet, head, viscera, gonads and half carcass (right part of the fish not including all parts previously removed, and corresponding to vertebral axis + skin-on untrimmed right fillet). Compartments were individually weighed to the nearest $0.5 \mathrm{~g}$, except viscera and gonads which were weighed to the nearest $0.1 \mathrm{~g}$. Sex was determined by visual inspection of the gonads. The following direct measurement were available for each fish: body length (BL, 
ATOL:0001658, in $\mathrm{cm}$ ) and body weight (BW, ATOL: 0000351, in g), viscera weight (ViscW, ATOL:0002258, in g), head weight (HeadW, ATOL:0001545, in g), skin-on untrimmed left fillet weight (leftFilW, ATOL:0002304, in g) and half carcass weight (HCarcW, in g). A new set of derived variables was created combining the previous traits: Condition Factor or $\mathrm{K}=100 * \mathrm{BW} / \mathrm{BL}^{3}$ (ATOL:0001653), and 5 composite weight traits (Table 1): carcass weight (CarcW, ATOL:0001057, in g), headless gutted carcass weight (HGCarcW, ATOL:0002260, in g), fillet weight (FilW, ATOL:0002304, in g) and vertebral axis weight (AxisW, in g). In addition, six yield percentages were calculated by dividing the weight of the different body compartments by total body weight (Table 1): fillet yield (Fil\%, ATOL:0002305), head yield (Head\%), headless gutted carcass yield (HGCarc\%, ATOL:0002261), carcass yield (Carc\%, ATOL:0000548), vertebral axis yield (Axis\%) and viscera yield (Visc\%). Moreover, considering both possible scale effects and the problems linked to estimating the heritability of a ratio (Gunsett, 1987), log-transformed variables were calculated. Natural logarithm was computed for the weight of all body compartments. The logtransformed body compartments were regressed on the logarithm of BW to obtain BW-independent allometric residuals (Logr_Carc, Logr_HGCarc, Logr_Fil, Logr_Head, Logr_Axis, Logr_Visc).

\section{Ultrasound tomography data collection.}

A series of internal measurements were performed on each fish through ultrasound imagery (Hospimedi, LC100, 7.5 MHz) using Haffray et al. (2013) positions reported in Fig. 2. The scans obtained resulted in 9 muscular thicknesses (from Echo1 to Echo9) and the internal depth of the body cavity (Echo23). Thicknesses were individually collected from anterior (Echo1, Echo4, Echo7), intermediate (Echo2, Echo5, Echo8) and posterior (Echo3, Echo6, Echo9) muscles in the dorsal, lateral and ventral position relative to the lateral line (Fig. 2). In order to compare ultrasound measurements among fishes, ratios of these variables were computed dividing ultrasound thickness by individual $\mathrm{BL}$ according to the following formula:

$R_{-}$echoi $=E c h o i / B L$, where Echoi is the ultrasound measurement at the $i_{t h}$ survey point and $B L$ is the individual body length.

\section{Image analysis.}

Thirty coordinates of morphological points with biological meaning (landmarks and semilandmarks) were obtained by semi-automated processing of the digital pictures using Visilog® software (FEI Visualization Sciences Group). Photo processing was realized at the INRA Laboratory of Fish Physiology and Genomics (Rennes, France). Briefly, after graphical positioning of the head and tail extremity of the fish, a macro-command adapted the scale of the picture to the 
selected size so that all fish had a similar size on the screen during the landmark positioning operation. Several blue lines divided the image in equidistant sections in in order to facilitate the manual positioning of landmarks and semi-landmarks on the surface of the fish (Fig. 2). Each point was characterized by two coordinates $(x, y)$ and the Euclidean distance between two landmarks A and

$d=\sqrt{\left(x_{B}-x_{A}\right)^{2}+\left(y_{B}-y_{A}\right)^{2}}$. A set of these segments was used to delimit 28 triangles (Fig. 3a) whose areas were calculated using the following formula:

$$
\text { area }=1 / 2\left|\left(x_{B}-x_{A}\right)\left(y_{C}-y_{A}\right)-\left(x_{C}-x_{A}\right)\left(y_{B}-y_{A}\right)\right|
$$

where the subscripts $\mathrm{A}, \mathrm{B}$ and $\mathrm{C}$ refer to the three vertices of a triangle.

The sum of different triangle combinations gave 12 representative surfaces covering the entire shape of each fish (Fig. 3b). In order to assess shape rather than size, proportion of the surfaces (relative to the total body surface) were preferred for a better comparison among fish. Proportions were computed as the following ratio: $P_{-} X=S_{-} X / S_{\text {tot }}$, where for each fish $S_{-} X$ is the surface of body part $X$ and $S_{\text {tot }}$ is the sum of all surfaces. Moreover, the distance between landmarks 1 and 30, representing the $2 \mathrm{D}$ Fork Length, due to its more accurate evaluation, were used as total Body Length (BL) in substitution of the on-site measurement.

\section{Phenotype data editing.}

The sum of the weights of the body compartments was compared with the total body. Fish with a sum of body compartments greater than the original body weight or with a $>2 \%$ weight loss were discarded from the analysis. In addition, linear regression between traits (BW against BL and all body compartments against BW) was used to identify bivariate errors. Animals with residuals greater than three times the standard error of the regression residuals for each bivariate combination of traits were discarded. Values of proportions of surfaces and ratios of ultrasound measurements outside 3 standard deviations around the mean were treated as missing values. Animals with undetermined sex were not included in the analysis.

\section{Prediction models.}

The residuals of the log-log regressions between weights of compartments and total BW were used as a surrogate for percent yields and treated as dependent variables in a series of multiple regressions investigating different combination of independent variables (Table 3). Categories of independent variables combinations tested were: 1) only proportions of surfaces, 2) only ratios of ultrasound measurements, 3) a combination of proportions of surfaces and ultrasound ratios, 4) a combination of the most significant variables in the model 3 and $4_{\text {bis }}$ ) similar to 4 but characterized 
by the substitution of the proportion of the head surface with the "square head proportion" (SQ_Head). The formula to calculate SQ_Head was: $\left(d_{1 \_6} \cdot d_{4 \_11}\right) / d_{1 \_30}{ }^{2}$, where $d_{1 \_6}$ and $d_{4 \_11}$ are the distances between the landmarks $1-6$ and $4-11$ and $d_{1 \_30}{ }^{2}$ is the square of BL. This measurement was tested as a surrogate to relative head surface as it can be measured directly on the field with a caliper. Multiple regression models were fitted with the REG procedure of $\mathrm{SAS} \otimes$ software. For each model, a stepwise method was used, $\mathrm{R}^{2}$ was used as indicator of goodness of fit, and its maximization as the criterion to choose the next variable to be added in the model (STEPWISE option for model selection in SAS REG). The final model chosen was the one which maximised $\mathrm{R}^{2}$ with all its independent variables being significant $(\mathrm{P}<0.05$, Fisher test). Prediction models were tested for fillet yield (models F1 to F4bis, see Table 3) and carcass yield (models C1 to C4bis), both considered the major objectives for the sea bass selection on processing yields. For each model, the linear predictor was computed for each fish and added to the phenotype file.

\section{DNA analysis and genotype data editing.}

The fin samples were stored in 95\% ethanol and sent to LABOGENA-DNA, the French laboratory for livestock genotyping (ISO 17025 accredited, Jouy-en-Josas, France), that provided the DNA analysis using 12 microsatellite markers. Parentage was assessed with software VITASSIGN version 8.5.2. (Vandeputte et al., 2006). The simulated exclusion power of the marker set was $89.8 \%$ taking into account parental genotypes. Considering this and the fact that the usual error rate in microsatellite genotyping is lower than $1 \%$ at LABOGENA-DNA, animals with no more than 2 allelic mismatches for a sire, dam, offspring triowere considered properly assigned following the recommendations of Vandeputte et al. (2006). Animals outside of the recorded mating design were discarded from further analysis.

\section{Quantitative genetic analysis}

Descriptive statistics (mean, standard deviation and coefficient of variation) and significance of effects were estimated using SAS ${ }^{\circledR}$ software. Mean and standard deviation were calculated for all fishes and for both sexes. Genetic parameters (heritability, correlations) were estimated with the following animal model using VCE 6.0 software (Groeneveld et al., 2008):

$Y=X \beta+Z \alpha+\varepsilon$

where $Y$ is the vector of observations (weights, proportion of surfaces, ultrasound ratios, yields, $\log$ $\log$ residuals of weights), $X$ and $Z$ are the incidence matrices of $\beta$ and $\alpha$, respectively the vectors of fixed effects (sex with 2 levels and mating plan with 3 levels corresponding to the 3 independent full-factorial blocks) and the vector of random additive genetic effects (825 levels corresponding to 
the records of the pedigree file), and $\varepsilon$ is the vector of random residual effects. Heritabilities were estimated with single trait models and genetic correlations through a series of bivariate models using all phenotypic data available from offspring. Parental fish had no own phenotypic records. Neither maternal effects nor dominance were introduced in the models. For dominance, the factorial nature of the design makes the additive component of variance unlikely to be biased by dominance. A random maternal effects was tested on body weight and found negligible $\left(\mathrm{m}^{2}<10^{-10}\right)$, so maternal effects were not considered further in the analysis.

The response to selection was estimated using the formulas of Falconer and McKay (1996) both for fillet and carcass percentage under a mass (MS), full sib (FS) and indirect (IS) selection. Genetic progress $(\Delta \mathrm{G})$ per generation for the theoretical MS based on direct (lethal) criteria was estimated applying the breeder's equation: $\Delta G=i h^{2} \sigma_{P}$, where $i$ is the selection intensity, $h^{2}$ and $\sigma_{P}$ are the heritability and phenotypic standard deviation of the trait for which genetic gain is estimated. Expected genetic gain for FS was estimated by: $\frac{i \sigma_{P} h^{2} n r}{\sqrt{n(1+(n-1) t)}}$ where $n$ is the number of sibs sampled per family $(\mathrm{n}=10), r$ is the additive genetic correlation between sibs $(r=0.5$ for full sibs) and $t$ is the phenotypic intra class correlation equal to $r \cdot h^{2}$. The genetic progress obtainable through IS was estimated applying the following equation: $\Delta G_{2}=\mathrm{i} \cdot \mathrm{h}_{1} \cdot \mathrm{h}_{2} \cdot \mathrm{r}_{\mathrm{A}} \cdot \sigma_{\mathrm{P} 2}$, where $\Delta G_{2}$ is the genetic progress on the target trait, $h_{1}$ and $h_{2}$ are respectively the square roots of heritability of the predictor (on which selection is applied) and of the target trait, $r_{A}$ is the additive genetic correlation existing between the predictor and the target trait and $\sigma_{\mathrm{P} 2}$ is the phenotypic standard deviation of the target trait (Falconer and Mackay, 1996). The gains per generation ( $\Delta G$ in natural log units) were scaled back to percent body weight units, multiplying by the compartment mean percentage in the population before selection.

The relative efficacy of selection (RES) related to each predictor and to their component variables was estimated to evaluate their interest for performing indirect selection for the trait to predict. RES was computed as the variable part of the response to indirect selection equation above: $R E S=$ $h_{1}\left|r_{A}\right|$ where $h_{1}$ is the square root of the heritability of the predictor or of the component variable, and $\left|r_{A}\right|$ is the absolute value of the genetic correlation existing between the variables and the target trait.

Response to selection was evaluated both for fillet and carcass percentage under MS and FS with a proportion selected of $10 \%$ and $30 \%$, with 10 sibs per family in FS. For IS the correlated response generated by predictors and variables with high RES were tested only with a proportion selected of $10 \%$. The proportion selected of $10 \%$ appears feasible in individual or indirect selection, while not really relevant in sib selection, where it would lead to discarding too many families for conserving genetic variability. 


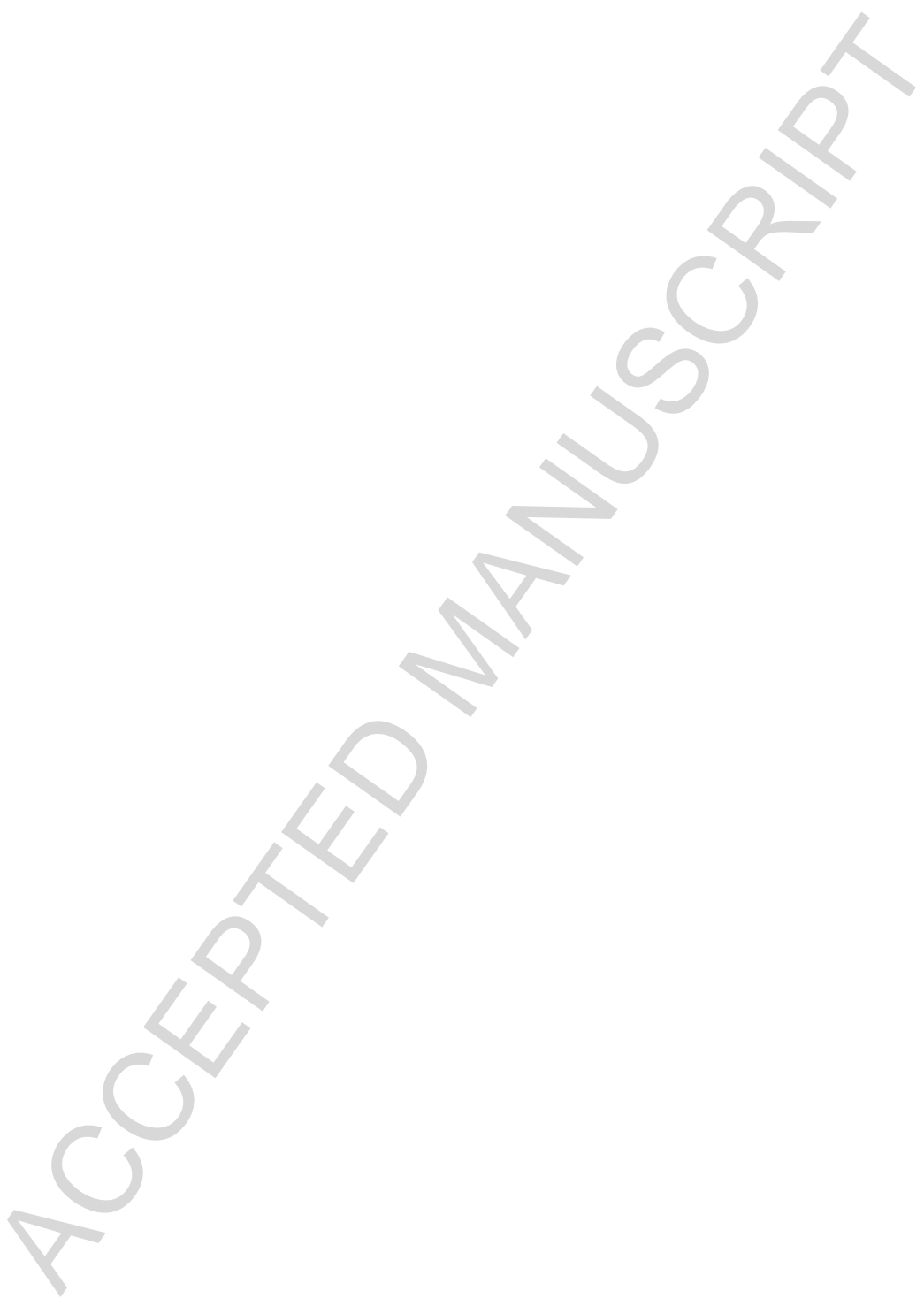




\section{Results.}

\section{Genotyping and parental assignment.}

A total of 915 offspring only gave some amplification, due to an unidentified DNA quality problem. From these, 830 were assigned to a single parental pair, with up to 2 mismatches allowed (90.7\%), 67 were assigned to multiple parent pairs $(7.4 \%)$ while $18(2.0 \%)$ were not assigned to any parent pair. Among the 830 fish correctly assigned, 34 that were not included in the declared mating plan and one with undetermined sex were removed from the dataset. After phenotypic data quality control, data from 760 fish (378 males, 382 females) with 60 variables were available, from 45 sire half-sib families (6-38 individuals per family - 2 sires gave no offspring), 20 dam half-sib families (7-100 individuals per family - 1 dam gave no offspring), and 264 full-sib families (1-14 individuals per family).

\section{Distribution of traits.}

Mean and standard deviation for weight and percentage traits for the overall population and among sexes are shown in Table 2. The average Carc\% and DGCarc\% were $88.9 \%$ and $69.7 \%$, respectively. Fil\% represented $57.4 \%$ of the whole body weight whereas head, vertebral axis and viscera accounted for $19.1 \%, 12.3 \%$ and $10.0 \%$ of the total $\mathrm{BW}$. A residual of $1.1 \%$ could be ascribed to gonads and body fluids losses that occurred on the slaughter chain. Distribution of sexes was homogeneous for the three mating plans with a little predominance of females in MP2 (55.5\%) and males in MP3 (53.3\%). The effect of sex and mating plan (MP) was significant for all weight traits, and for several percent traits (Table 2), so sex and mating plan were kept as fixed effects in all models.

\section{Prediction equations.}

Summary statistics for proportions of surfaces and ratios of ultrasound measurements to body length, which are the component traits used in prediction equations, are given in Supplementary Table S5, and the phenotypic correlations between those component traits are given in Supplementary Table S6. A total of 10 models were tested for the prediction of fillet and carcass percentage. Predicted yields were represented by the residual of the log-log regression of the trait on body weight (Table 3). Multicolinearity was reasonably low with a maximum variance inflation factor below 5 for any variable in any of the models. For the prediction of fillet percentage model F1 (proportion of surfaces) was obtained including 6 variables with a $\mathrm{R}^{2}$ of $16 \%$. Model F2, constituted by 3 ratios of ultrasound measurements, with a $\mathrm{R}^{2}$ of $2 \%$ was the least explicative of all 
models. Model F3, composed by 7 significant variables $(5$ surfaces and 2 ultrasound measurements), gave the best combinations in terms of phenotypic variance explained $\left(\mathrm{R}^{2}=18 \%\right)$ for fillet percentage. Model F4 and F4 bis had respectively a $\mathrm{R}^{2}$ of $14 \%$ and $11 \%$. Although maintaining the same pattern of relative values, $\mathrm{R}^{2}$ of the models for the prediction of carcass percentage were systematically higher than those obtained in the prediction of fillet percentage. In particular model C3 (7 surfaces and 3 ultrasound measurements) showed the best predicting ability $\left(\mathrm{R}^{2}=41 \%\right)$ while model C2 (4 ultrasound measurements) had the lowest efficiency $\left(\mathrm{R}^{2}=27 \%\right)$. Unlike models $\mathrm{F} 4$ and $\mathrm{F} 4$ bis, models $\mathrm{C} 4$ and $\mathrm{C} 4$ bis had comparable $\mathrm{R}^{2}$ values.

\section{Heritabilities}

Heritability was generally moderate for all variables. Heritability ( \pm standard error) for BW at slaughter was $0.41 \pm 0.09$, whereas heritability of $\mathrm{BL}$ and $\mathrm{K}$ were $0.38 \pm 0.09$ and $0.50 \pm 0.09$, respectively (Supplementary Table S1). Estimates obtained for all other carcass traits (weights of body parts) ranged from 0.36 to 0.41 (Supplementary Table S1). Heritabilities for the residuals of the log-log regression (Table 4) were comparable to those obtained for the percent yields (Supplementary Table S2) ranging from 0.16 (Logr_Axis) to 0.57 (Logr_Carc), with a relatively low value (0.21) for Logr_Fil. Heritabilities of predictors from models F1, F2, F3, as well as C2, C3 (Table 5), were lower than those obtained from the target traits (fillet and carcass percent), while the heritability of C1 was similar to that of Logr_Carc. Moreover, models F2 and C2 showed the lowest heritability compared to the other prediction models, for both target traits. Heritabilities of the predictors from models F4 and F4 bis were higher than those obtained for their target trait, Logr_Fil. Models C4 and C4 bis showed heritability estimates close to those obtained for their target trait, Logr_Carc.

\section{Genetic correlations.}

All body part weights showed a highly positive genetic (0.75 to 0.99 ) and phenotypic (0.78 to 0.99 ) correlation with each other (Supplementary Table S1). The condition coefficient K also showed a positive, but lower genetic ( 0.61 to 0.85$)$ and phenotypic ( 0.55 to 0.81$)$ correlation with the weights of body parts. Genetic correlations between percent traits and log-residual traits were close to unity (Supplementary Table S3). Genetic correlations between yields estimated by log residuals were generally positive (Table 4), except for correlations between viscera and the other parts, which were negative (- 0.25 to -0.99$)$, and correlations between fillet and head or axis (- 0.19 and -0.31 , respectively). Carcass and fillet yields were genetically independent $\left(\mathrm{r}_{\mathrm{A}}=-0.01 \pm 0.20\right)$, while the genetic correlation between Logr_Fil and Logr_Carc was positive but rather low and imprecise $(0.28 \pm 0.20)$. The genetic correlation of Logr_Fil with Logr_HGCarc was much higher $(0.79 \pm$ 
0.09). Genetic correlations obtained between target traits and predictors (Table 5) were lower for those predicting fillet yield ( 0.12 to 0.67$)$ than for those predicting carcass yield (0.91 to 0.95$)$. Predictors of Logr_Carc showed higher correlations with each other (0.80 to 0.98) than predictors of Logr_Fil (0.0063 to 0.87). The correlation between models F2 and F4 ${ }_{\text {bis, }}$ was the lowest (0.006). Although the genetic correlation between Logr_Fil and Logr_Carc was weakly positive (see above), the genetic correlation between predictors of Logr_Fil and predictors of Logr_Carc was always (and sometimes strongly) negative (- 0.12 to - 0.77). The genetic correlations between predictors of Logr_Fil (F1 to F4 bis) and Logr_Carc was also always negative (- 0.20 to -0.56$)$ while the correlation between predictors of Logr_Carc (C1 to C4bis) and Logr_Fil was weakly positive (0.03 to 0.26$)$.

\section{Relative efficiency of indirect predictors.}

The relative efficacy (RES) of predictors and their component variables was computed individually. Heritability estimates, genetic correlations with Logr_Fil and Logr_Carc and RES of the proportion of surfaces, ratios of ultrasound measurements and composite predictors are shown in Supplementary Table S4. Values of RES were generally higher for variables and predictors involved in the prediction of carcass than in that of fillet. Logr_Carc predictors showed the best results of RES (0.52 to 0.70). Two simple variables, P_Head and R_Echo23, showed values of RES (0.54 and 0.51, respectively) comparable to Logr_Carc predictors (Table S4). Ranging from 0.07 (F4bis) to 0.28 (F3), RES of fillet yield predictors was in all cases lower than RES of carcass yield predictors. The highest RES was obtained with F3 and F4 predictors (0.28 and 0.27) only marginally higher than with the simple R_Echo9 variable (0.23). No predictor or single trait showed both a high efficiency for increasing fillet and carcass yield, the best single traits being R_Echo23 and P_Head.

\section{Expected Genetic Gain.}

Estimation of genetic gains was performed using the genetic and phenotypic parameters of the different traits and predictors. Gains obtained for selection on carcass yield were higher than those obtained for selection on fillet yield in all cases of direct selection. Under the hypothetical mass selection for yields (not feasible in practice as involving the sacrifice of the animals), genetic gains achievable per generation for the two intensities of selection tested ranged from 1.13 to $1.71 \%$ per generation for carcass percentage and from 0.38 to $0.57 \%$ for fillet percentage (Table 6). Genetic gain for FS with 10 sibs selected per family and 30\% selection pressure was $0.95 \%$ for carcass yield and $0.43 \%$ for fillet yield. Genetic gains obtained by indirect selection (IS) were also higher for carcass yield than for fillet yield. Genetic gain achieved applying carcass predictors ranged from 
$1.18 \%$ to $1.58 \%$, whereas fillet predictors resulted in gains between $0.09 \%$ and $0.36 \%$. Indirect selection applied with simple variables (R_Echo23 and P_Head) again showed better gains for carcass $(1.17 \%$ and $1.22 \%)$ than for fillet yield $(0.14 \%$ and $0.16 \%)$. Correlated response in carcass percent when selecting on fillet predictors was negative, while this was not the case for fillet percent when selection was performed on carcass predictors. No method could achieve both a high gain in fillet percent and a high gain in carcass percent.

\section{Discussion}

This study provides for the first time a complete description of growth and processing traits in European sea bass, including the knowledge of their genetic parameters (heritability and genetic correlations) and the potential genetic gain for processing traits in different breeding strategies. Results were however only obtained for one strain and in one environment and extension to other strains or environments should then be considered with caution. Previous studies had estimated genetic parameters for fillet percent in European sea bass either on a small family setting (27 families from 9 sires and 3 dams parents from West Mediterranean origin - Saillant et al., 2009), on different populations derived from wild parents (Vandeputte et al., 2014) or on the same population (Bestin et al., 2014). Here, we also predicted processing yields using morphological traits obtained from external (digital photo) and internal but non-lethal (ultrasound imagery) measurements. This was done with the aim to replace selection methods implicating the sacrifice of the individuals (mass selection, not feasible in practice on lethal traits) or their relatives (sib selection), by direct selection of candidates based on the use of predictors as indirect criteria. In Nile tilapia (Oreochromis niloticus), Rutten et al. (2004) performed a similar approach, with morphological measurements, to predict both fillet weight and fillet yield. Combining extermal morphology and ultrasound has been done in catfish (Ictalurus spp) by Bosworth et al. (2001) to identify high meatproducing individuals through the phenotypic relationships between body shape and ultrasound images of muscle sections. Sang et al. (2009) estimated phenotypic fillet weight and fillet yield using six body measurements (including volume) and four circumferences integrated in a multiple regression model in a reference population composed by 200 river catfish (Pangasianodon hypophthalmus). Haffray et al. (2013) predicted processing yields through multiple linear regression models comprising external morphology and ultrasound measurements, providing genetic parameters and theoretical gains achievable applying predictors for the direct selection of live candidates in rainbow trout. Recently Perazza et al. (2015) also estimated phenotypically loin-eye area in tambaqui (Colossoma macropomum) using ultrasounds. To our knowledge this study is the first large scale analysis on fillet yield prediction for a Mediterranean fish species reared under 
commercial conditions, integrating ultrasound imagery and body shape measurements in a pedigreed population. 


\section{Fixed effects}

Effects of sex and mating plan were seen on all weight traits and some of the yields. The effect of mating plan can be explained by heterogeneity in the composition of the female groups used, and this heterogeneity can be of genetic (different subsets of the selection nucleus) or environmental (egg quality in separately reared female groups) origin. However, as we used mating plan as fixed effect, this is not expected to bias genetic parameter estimates as long as these subgroups are a representative sample of the selection nucleus. Females tended to have a lower fillet yield compared to males $(-0.2 \%)$, but this difference was not significant contrary to that reported by Saillant et al. (2009), who found a difference among sexes of $2.4 \%$. A size effect may be hypothesised to explain this difference as fish from Saillant et al. (2009) were almost twice as big as the fish processed in the present study (741 g vs 395 g). The older fish recorded by Saillant et al. (2009) were sexually maturing, while here gonads were on average smaller than $1 \%$ of the body weight, and this may explain the difference. The only significant sexual dimorphism reported here for percent traits were for head yield $(\mathrm{F}>\mathrm{M})$, headless gutted carcass yield $(\mathrm{F}<\mathrm{M})$ and axis yield $(\mathrm{F}<\mathrm{M})$ as reported in Table 2.

\section{Genetic parameters of carcass and processing traits.}

The heritability estimates for BW (0.40) and K (0.50) were intermediate to high when compared with previous experiments in sea bass where they ranged from 0.19 to 0.63 for BW and 0.10 to 0.49 for K (Bardon et al., 2009; Dupont-Nivet et al., 2008, 2010; Haffray et al., 2007; Karahan et al., 2013; Saillant et al., 2006, 2009; Vandeputte et al., 2014). Heritability estimates are also in the upper range for $\mathrm{Carc} \%(0.57$ vs 0.48 - 0.74), equivalent (0.20 vs 0.20 - 0.25) for Fil\% and lower ( 0.46 vs 0.87 ) for $\mathrm{Head} \%$ when compared with previous studies on different populations (Haffray et al., 2007; Saillant et al., 2009; Vandeputte et al., 2014). Compared to another year class of the same strain estimated in the previous generation of selection (Bestin et al., 2014), heritability was higher in the present study for BW (0.40 vs 0.19), K (0.50 vs 0.37) and Head\% (0.46 vs 0.32) and similar for Carc\% (0.57 vs 0.54), HGCarc\% (0.32 vs 0.35) and Fil\% (0.20 vs 0.20). Our results also confirm that after 4 generations of selection, the EMG line exhibited high genetic variation for growth and processing traits, with similar or higher heritability estimates, similar phenotypic CVs of processing traits (ranging from 2 to $8 \%$ in both cases) and a higher phenotypic CV of BW (32\% here vs. $23 \%$ in Bestin et al., 2014).

The weights of body parts were highly correlated both genetically and phenotypically, and had a heritability close to that of body weight, as generally seen in this type of studies - there is much 
more phenotypic variation in body size and weight than in proportions of the different body parts. Fillet and carcass percent were approached both by the ratio trait and by the residual of the log-log regression of the body part weight on body weight, as proposed earlier (Haffray et al., 2013; Vandeputte et al., 2014). Log-residuals and yields had similar heritability $(0.20-0.21$ for fillet yield, 0.57 for carcass yield) and were very highly genetically correlated $(>0.99)$ showing they describe the same trait.

The present study showed a low genetic correlation between carcass yield and fillet yield $(-0.01 \pm$ 0.20 with the ratio trait or $0.28 \pm 0.20$ with the $\log$ residuals,) as previously reported in sea bream ($0.05 \pm 0.19$, Navarro et al., 2009) but not in in rainbow trout $(0.75 \pm 0.03$, Haffray et al., 2012)

This low genetic correlation may be due to the fact that head yield has a strongly positive genetic correlation with carcass yield (0.87 to 0.90$)$, so that sea bass with high carcass percentage are also sea bass with a large head, while this correlation was very weak in rainbow trout $(0.03$ to 0.13 , Haffray et al., 2012). In addition, the genetic correlations between head yield and fillet yield were negative (- 0.19 to -0.41$)$ as reported earlier in sea bass (- 0.73) by Saillant et al. (2009), rainbow trout (- 0.50 to - 0.53, Haffray et al., 2012; - 0.14 Kause et al., 2007) and tilapia (- 0.94, Rutten et al., 2005). Head yield had a very high mean value in our experiment $(19.1 \%)$ when compared to rainbow trout (11.1\%, Haffray et al., 2012). This difference in relative importance of head, fillet and viscera between species may lead to different types of genetic and phenotypic relationships between those traits. In sea bass, Head\% is not only high, but its coefficient of variation within the population is also much higher $(8.4 \%)$ than that of other body parts $(2.1 \%$ for Carc $\%$; $2.8 \%$ for Fil\%), questioning the evolutionary basis for such high variation, which may then have unexpected consequences when selecting specifically fish with a smaller head.

\section{Predictors}

We evaluated the use of headless gutted carcass yield as a possible lethal predictor of fillet yield not requiring the error-prone filleting operation, as reported in rainbow trout (Haffray et al., 2013). This trait had a heritability higher than that of fillet yield (0.32 vs. $0.20-0.21)$ and a reasonably high genetic correlation with fillet yield $(0.72-0.79)$, but the figures were less favourable than in rainbow trout $\left(\mathrm{h}^{2}=0.54-0.55, \mathrm{r}_{\mathrm{A}}=0.97-0.98\right.$, Haffray et al., 2013). The use of headless gutted carcass yield as a surrogate for fillet yield in slaughtered sibs (faster measurement, less subject to errors) in this population of sea bass is thus not as straightforward as it is in rainbow trout.

Through a multiple linear regression approach we selected ten models (five types per character to predict), to indirectly predict fillet (F) and carcass (C) percentage. Models F1 and C1 (using 
proportion of surfaces as predictors) as well as F2 and C2 (using ratios of ultrasound measurements), gave medium to low values of $\mathrm{R}^{2}$. The lower $\mathrm{R}^{2}$ and lower heritability of $\mathrm{F} 2$ and $\mathrm{C} 2$ models could be related to the low heritability values estimated for from ratios of ultrasound measurements. These poorer results may be linked to measurement errors, which are easily done through inexact positioning of the probe $\left(\mathrm{h}^{2} \leq 0.10\right.$ for $\mathrm{R}$ _echo1, $\mathrm{R}$ _echo2, $\mathrm{R}$ _echo3, see Table S4) or measurement of small distances (for $\mathrm{R}$ echo 7 and $\mathrm{R}$ _echo8, see Table S4). It is symptomatic that the highest heritability estimates were obtained for the ultrasound measuring the largest distance ( $\mathrm{R}$ _echo23, depth of the body cavity, $\mathrm{h}^{2}=0.38$ ) or measuring fillet thickness at well-defined points on the lateral line ( $\mathrm{R}$ _echo 4 to $6,0.17 \leq \mathrm{h}^{2} \leq 0.24$ ). We also have to mention that in this case, all fish in the dataset were used to set up the regression equations, and not only the $10 \%$ higher or lower performers as in Haffray et al. (2013), which may also have contributed to the apparently lower precision of phenotypic prediction.

In order to simplify phenotyping, especially in fish farms and/or in a context of real-time measurement to integrate the predictors in an hypothetical automated sorting system, we tested models (F4, F4 bis, $\mathrm{C} 4, \mathrm{C} 4$ bis $)$ with less, easier to measure variables such as the relative head surface (F4 and C4) or the relative surface of a square containing the head (SQ_Head, F4 $4_{\text {bis }}$ and $\mathrm{C}_{\text {bis }}$ ) together with the depth of the abdominal cavity R_Echo23, that was shown (Table S4) to have a high potential for predicting the genetic variation of both fillet and carcass yield. In the case of carcass yield, the model including both surfaces and ultrasound measurements (C3) performed better than models $\mathrm{C} 1$ and $\mathrm{C} 2\left(\mathrm{R}^{2}=0.41\right.$ vs 0.33 and 0.27$)$. The simplified models ( 44 and $\mathrm{C} 4$ bis $)$ were equivalent to each other $\left(\mathrm{R}^{2}=0.36\right.$ for both), justifying the application of the SQ_Head. Models $\mathrm{C} 4$ and $\mathrm{C}_{\text {bis }}$ were also characterized by the presence of dorsal $\left(\mathrm{P}_{-} 2 \mathrm{D}\right)$ and ventral $\left(\mathrm{P}_{-} 2 \mathrm{~V}\right)$ proportion of the body surfaces below the first dorsal fin. The coefficients of these two body surfaces were positively (dorsal) and negatively (ventral) related with the carcass yield. Moreover, the regression coefficients for the head were positive in all five carcass yield models confirming as seen before that fish with large heads also have a high phenotypic carcass percentage. In the end P_Head (or alternatively SQ_Head), $P_{-} 2 \mathrm{D}$ and $\mathrm{P} \_2 \mathrm{~V}$, jointly to R_echo23, were the measurements with the highest explanatory power for carcass yield. Heritability estimates of carcass yield predictors, ranging from 0.33 to 0.57 , were generally close to the heritability of the target trait Logr_Carc (0.57). Genetic and phenotypic correlations between predictors and carcass yield were high (0.91 to 0.95 - Table 5), thus making them suitable for indirect selection on live candidates $(+1.18$ to $1.58 \%$ carcass per generation with $10 \%$ selected - Table 5), better than sib selection on slaughtered sibs (0.95\% gain with $30 \%$ selected, $1.43 \%$ with $10 \%$ selected). Carcass predictors 
were also positively correlated with fillet yield, and gave positive (albeit very low) responses in fillet percentage ( 0.03 to $0.20 \%)$.

The prediction capability of fillet predictors was generally lower than that of carcass predictors. The best model including only proportion of surfaces (F1) gave a $\mathrm{R}^{2}$ of $16 \%$, and F3 was the best model with a $\mathrm{R}^{2}$ of $18 \%$. The simplified models $\mathrm{F} 4$ and $\mathrm{F} 4$ bis exhibited lower values of $\mathrm{R}^{2}(0.14$ and 0.11 , respectively). In terms of potential genetic gains, the best fillet predictors were F3 and F4 which gave $0.36 \%$ and $0.34 \%$ of fillet gains, respectively, with a proportion selected of $10 \%$. However, they were outperformed by sib selection which gave $0.65 \%$ gain in fillet yield with the same proportion selected. Still, selecting only $10 \%$ of the families in sib selection may be problematic to keep enough genetic variability, and in this case a proportion selected of $30 \%$ is more realistic. With this more realistic selection intensity, sib selection on fillet yield gave rather similar results $(0.43 \%$ gain per generation) compared to indirect selection with predictors (up to $0.36 \%$ per generation). Interestingly, while when selecting on carcass yield predictors (see before), there was a correlated increase in fillet yield, selection on any fillet predictor provided negative gains on carcass yield (0.17 to $-0.73 \%$ ). This means that the two types of predictors did not act on the same parts of the sea bass body. This is especially due to the importance of head surface in fillet yield models, which, contrary to what is seen in carcass predictors, has negative coefficients in fillet predictors and thus opposite results.

Then, selecting for improved fillet percentage in sea bass cannot follow the general and easy picture in fish of increasing carcass percentage (Haffray et al., 2012; Kause et al., 2007; Kocour et al., 2007; Rutten et al., 2005) and decreasing head size (Haffray et al., 2012; Kocour et al., 2007; Rutten et al., 2005), as head size has opposed effects on carcass yield and fillet yield. Sib selection on both carcass and fillet yield could be an opportunity and should create genetic progress on the two traits, as they are weakly if at all genetically correlated. Selection using predictors needs to be considered with caution to not deteriorate fillet yield when selecting to improve carcass yield or vice versa. These unusual results may be linked to the population or the rearing conditions used, and should be confirmed with similar studies in other sea bass populations or farming environments, also considering factors that may interact with fat deposition in the viscera, such as feed composition. More generally, this study highlighted that the relative development of different body compartments might be rather species specific, and requires further studies to be able to draw a more general picture. 


\section{Acknowledgements}

This work was financed by France Agrimer under the BAR-3D project (convention SIVAL NL: 2012-0302). Antonio Puledda was financed by the Erasmus-plus mobility programme.

Tables

Table 1.

Traits recorded and calculated for the different body compartments.

\begin{tabular}{lllll}
\hline body compartment & weight trait & combination of variables & $\begin{array}{l}\text { Yield trait } \\
\text { (traitW/BW) }\end{array}$ & $\begin{array}{l}\text { Log residual trait } \\
\text { (log_trait } \sim \text { log_BW) }\end{array}$ \\
\hline Fillet & FilW & LeftFilW x 2 & Fil\% & Logr_Fil \\
Head & HeadW & HeadW & Head\% & Logr_Head \\
Headless Gutted Carcass & HGCarcW & HalfCarcW + LeftFilW & HGCarc\% & Logr_HGCarc \\
Total Carcass & CarcW & HGCarcW + HeadW & Carc\% & Logr_Carc \\
Axis & AxisW & HGCarcW - (2 x leftFillW) & Axis\% & Logr_Axis \\
Viscera & VisceraW & VisceraW & Viscera\% & Logr_Viscera \\
\hline
\end{tabular}

Table 2.

Mean and standard deviation for processing traits (weights and percent yield) in males and females of European sea bass (Dicentrarchus labrax L.). P.values are given for the differences between males and females for each trait..

\begin{tabular}{|c|c|c|c|c|c|c|}
\hline Trait & Mean \pm S.D. & Males & Females & P-value & Min. & Max. \\
\hline \multicolumn{7}{|l|}{ Weights } \\
\hline BW & $395.4 \pm 127.1$ & $356.4 \pm 113.4$ & $433.9 \pm 128.4$ & $<.0001$ & 115.0 & 783.0 \\
\hline CarcW & $350.2 \pm 108.8$ & $316.1 \pm 96.8$ & $384.1 \pm 109.6$ & $<.0001$ & 104.5 & 690.0 \\
\hline HGCarcW & $275.5 \pm 87.8$ & $249.5 \pm 79.2$ & $301.3 \pm 88.3$ & $<.0001$ & 78.5 & 545.5 \\
\hline FilW & $227.6 \pm 74.7$ & $205.8 \pm 67.6$ & $249.2 \pm 75.1$ & $<.0001$ & 62.0 & 453.0 \\
\hline HeadW & $74.7 \pm 21.7$ & $66.6 \pm 18.1$ & $82.8 \pm 21.9$ & $<.0001$ & 26.0 & 144.5 \\
\hline AxisW & $47.9 \pm 13.9$ & $43.7 \pm 12.3$ & $52.1 \pm 14.2$ & $<.0001$ & 14.5 & 99.0 \\
\hline VisceraW & $41.0 \pm 18.4$ & $37.3 \pm 17.0$ & $44.6 \pm 19.1$ & $<.0001$ & 8.2 & 120.6 \\
\hline \multicolumn{7}{|c|}{ Yields (percent of BW) } \\
\hline Carc\% & $88.9 \pm 1.9$ & $89.0 \pm 2.0$ & $88.8 \pm 1.9$ & ns & 81.3 & 94.0 \\
\hline HGCarc $\%$ & $69.7 \pm 1.2$ & $69.9 \pm 1.3$ & $69.5 \pm 1.2$ & $<.0001$ & 65.7 & 73.9 \\
\hline Fil\% & $57.4 \pm 1.6$ & $57.5 \pm 1.7$ & $57.3 \pm 1.6$ & ns & 50.1 & 62.9 \\
\hline Head $\%$ & $19.1 \pm 1.6$ & $19.0 \pm 1.7$ & $19.3 \pm 1.6$ & 0.0085 & 14.7 & 24.9 \\
\hline Axis $\%$ & $12.3 \pm 1.3$ & $12.4 \pm 1.4$ & $12.1 \pm 1.2$ & 0.0014 & 9.2 & 16.8 \\
\hline Viscera $\%$ & $10.0 \pm 1.9$ & $10.1 \pm 1.9$ & $10.0 \pm 1.9$ & ns & 5.4 & 17.4 \\
\hline
\end{tabular}




\section{Table 3.}

Multiple regression models for the prediction of fillet and carcass percentage with type and name of models, linear combination of variables used to obtain predictors and relative $\mathrm{R}^{2}$. Models F1-F4bis relate to prediction of fillet percentage, models C1-C4bis to prediction of carcass percentage. The

\begin{tabular}{|c|c|c|c|c|}
\hline $\begin{array}{c}\text { Model } \\
\text { type }\end{array}$ & $\begin{array}{l}\text { Model } \\
\text { Name }\end{array}$ & Linear combination of coefficients and variables & $\underset{\mathbf{R}^{2}}{\text { Adjusted }}$ & Max VIF \\
\hline I & $\mathrm{F} 1$ & $\begin{array}{c}0.27-1.25 \text { P_Head }-0.48 \text { P_1V }+0.31 \text { P_2D }-0.36 \text { P_2V } \\
-0.57 \text { P_3D }+0.70 \text { P_Tail }\end{array}$ & 0.16 & 3.79 \\
\hline II & $\mathrm{F} 2$ & $-0.07+0.52$ R_echo $2+0.70$ R_echo7 +1.84 R_echo 9 & 0.02 & 1.01 \\
\hline III & F3 & $\begin{aligned} 0.227-1.25 & \text { P_Head }-0.29 \mathrm{P} \_1 \mathrm{~V}+0.49 \mathrm{P} \_2 \mathrm{D}-0.18 \mathrm{P} \\
& +1.30 \mathrm{R} \_ \text {echo8 }-0.48 \mathrm{R} \_ \text {echo23 }\end{aligned}$ & 0.18 & 1.85 \\
\hline IV & F4 & $0.26-1.17$ P_Head -0.60 R_echo23 & 0.14 & 1.38 \\
\hline IVbis & F4bis & $0.17-4.08$ SQ_Head & 0.11 & 1.00 \\
\hline I & $\mathrm{C} 1$ & $-0.06+0.64 \mathrm{P}_{-} \mathrm{Head}-0.90 \mathrm{P}_{-} 1 \mathrm{D}+1.21 \mathrm{P}_{-} 2 \mathrm{D}-0.56 \mathrm{P} \_2 \mathrm{~V}$ & 0.33 & 3.11 \\
\hline II & $\mathrm{C} 2$ & $0.05-0.31$ R_echo6 +0.54 R_echo7 +1.95 R_echo8 -0.70 R_echo 23 & 0.27 & 1.19 \\
\hline III & $\mathrm{C} 3$ & $\begin{array}{c}0.08+0.35 \text { P_Head }-0.90 \text { P_1D }+1.17 \text { P_2D }-0.57 \cdot \mathrm{P} \_2 \mathrm{~V}-1.10 \mathrm{P} 5 \mathrm{D}+0.36 \mathrm{P} \_5 \mathrm{~V} \\
-0.75 \text { P_Tail }+0.42 \mathrm{R} \_ \text {echo7 }+1.56 \mathrm{R} \_ \text {echo } 8-0.53 \cdot \mathrm{R} \_ \text {echo } 23\end{array}$ & 0.41 & 4.46 \\
\hline IV & $\mathrm{C} 4$ & $-0.01+0.41 \mathrm{P}_{-} \mathrm{Head}+0.79 \mathrm{P} \_2 \mathrm{D}-0.33 \mathrm{P} \_2 \mathrm{~V}-0.45 \mathrm{R} \_$echo23 & 0.36 & 1.53 \\
\hline IVbis & C4bis & $0.007+0.78$ P_2D -0.33 P_ $2 \mathrm{~V}+1.74 \mathrm{SQ} \_$Head $-0.65 \mathrm{R} \_$echo23 & 0.36 & 1.53 \\
\hline
\end{tabular}

maximum variance inflation factor (VIF) for any variable in each model is given.

Table 4.

Heritability and standard error (diagonal), genetic correlation and standard error (above the diagonal), phenotypic correlations (below the diagonal) for processing traits obtained as residual of the linear regression between logarithm of body compartment and logarithm of body weight in European sea bass (Dicentrarchus labrax L.).

\begin{tabular}{lccccccc}
\hline & BW & Logr_Carc & Logr_HGCarc & Logr_Fil & Logr_Head & Logr_Axis & Logr_Visc \\
\hline BW & $\mathbf{0 . 4 1} \pm \mathbf{0 . 0 9}$ & $-0.12 \pm 0.17$ & $-0.04 \pm 0.20$ & $0.01 \pm 0.21$ & $-0.18 \pm 0.18$ & $-0.11 \pm 0.22$ & $0.12 \pm 0.18$ \\
Logr_Carc & -0.03 & $\mathbf{0 . 5 7} \pm \mathbf{0 . 1 1}$ & $0.77 \pm 0.08$ & $0.28 \pm 0.20$ & $0.87 \pm 0.05$ & $0.72 \pm 0.13$ & $-0.99 \pm 0.002$ \\
Logr_HGCarc & 0.06 & 0.64 & $\mathbf{0 . 3 2} \pm \mathbf{0 . 0 8}$ & $0.79 \pm 0.09$ & $0.36 \pm 0.18$ & $0.33 \pm 0.23$ & $-0.76 \pm 0.09$ \\
Logr_Fil & 0.05 & 0.21 & 0.66 & $\mathbf{0 . 2 1} \pm \mathbf{0 . 0 8}$ & $-0.19 \pm 0.23$ & $-0.31 \pm 0.24$ & $-0.25 \pm 0.20$ \\
Logr_Head & -0.11 & 0.71 & -0.06 & -0.32 & $\mathbf{0 . 4 4} \pm \mathbf{0 . 1 0}$ & $0.78 \pm 0.12$ & $-0.88 \pm 0.05$ \\
Logr_Axis & -0.003 & 0.41 & 0.2 & -0.59 & 0.35 & $\mathbf{0 . 1 6} \pm \mathbf{0 . 0 6}$ & $-0.74 \pm 0.12$ \\
Logr_Visc & 0.06 & -0.96 & -0.62 & -0.17 & -0.69 & -0.42 & $\mathbf{0 . 5 6} \pm \mathbf{0 . 1 1}$ \\
\hline
\end{tabular}


Table 5.

Heritability and standard error (diagonal), genetic correlations \pm standard error (above the diagonal) and phenotypic correlations (below the diagonal) for growth and carcass traits in European sea bass (Dicentrarchus labrax L.). Predictors F1-F4bis relate to prediction of fillet percentage, models C1-C4bis to prediction of carcass percentage

\begin{tabular}{|c|c|c|c|c|c|c|c|c|c|c|c|c|}
\hline & Logr_Fil & Logr_Carc & $\mathrm{F} 1$ & F2 & F3 & F4 & F4bis & $\mathrm{C} 1$ & $\mathrm{C} 2$ & $\mathrm{C} 3$ & $\mathrm{C} 4$ & C4bis \\
\hline Logr_Fil & $0.20 \pm 0.07$ & $0.28 \pm 0.20$ & $0.48 \pm 0.20$ & $0.22 \pm 0.26$ & $0.67 \pm 0.17$ & $0.52 \pm 0.20$ & $0.12 \pm 0.22$ & $0.03 \pm 0.23$ & $0.26 \pm 0.22$ & $0.14 \pm 0.21$ & $0.14 \pm 0.21$ & $0.22 \pm 0.21$ \\
\hline Logr_Carc & 0.21 & $0.57 \pm 0.10$ & $-0.46 \pm 0.18$ & $-0.20 \pm 0.23$ & $-0.22 \pm 0.21$ & $-0.56 \pm 0.15$ & $-0.55 \pm 0.13$ & $0.91 \pm 0.04$ & $0.91 \pm 0.04$ & $0.95 \pm 0.02$ & $0.94 \pm 0.03$ & $0.94 \pm 0.03$ \\
\hline $\mathrm{F} 1$ & 0.37 & -0.23 & $0.17 \pm 0.06$ & $0.61 \pm 0.20$ & $0.87 \pm 0.06$ & $0.78 \pm 0.10$ & $0.54 \pm 0.16$ & $-0.60 \pm 0.15$ & $-0.46 \pm 0.18$ & $-0.55 \pm 0.17$ & $-0.57 \pm 0.16$ & $-0.55 \pm 0.17$ \\
\hline $\mathrm{F} 2$ & 0.13 & 0.02 & 0.15 & $0.14 \pm 0.05$ & $0.49 \pm 0.22$ & $0.39 \pm 0.22$ & $0.006 \pm 0.25$ & $-0.41 \pm 0.22$ & $-0.35 \pm 0.22$ & $-0.29 \pm 0.23$ & $-0.40 \pm 0.21$ & $-0.30 \pm 0.21$ \\
\hline F3 & 0.39 & -0.09 & 0.90 & 0.18 & $0.18 \pm 0.07$ & $0.87 \pm 0.05$ & $0.63 \pm 0.13$ & $-0.48 \pm 0.17$ & $-0.12 \pm 0.21$ & $-0.30 \pm 0.19$ & $-0.35 \pm 0.19$ & $-0.34 \pm 0.18$ \\
\hline F4 & 0.34 & -0.25 & 0.78 & 0.08 & 0.88 & $0.27 \pm 0.08$ & $0.80 \pm 0.08$ & $-0.77 \pm 0.09$ & $-0.35 \pm 0.18$ & $-0.61 \pm 0.13$ & $-0.62 \pm 0.12$ & $-0.63 \pm 0.14$ \\
\hline F4bis & 0.26 & -0.25 & 0.66 & -0.06 & 0.69 & 0.77 & $0.36 \pm 0.08$ & $-0.57 \pm 0.12$ & $-0.17 \pm 0.19$ & $-0.49 \pm 0.14$ & $-0.43 \pm 0.15$ & $-0.52 \pm 0.14$ \\
\hline $\mathrm{C} 1$ & -0.07 & 0.67 & -0.33 & -0.05 & -0.30 & -0.57 & -0.44 & $0.57 \pm 0.10$ & $0.80 \pm 0.08$ & $0.96 \pm 0.02$ & $0.97 \pm 0.01$ & $0.97 \pm 0.02$ \\
\hline $\mathrm{C} 2$ & 0.02 & 0.68 & -0.31 & 0.06 & 0.002 & -0.07 & -0 & 0.56 & $0.33 \pm 0.08$ & $0.87 \pm 0.04$ & $0.91 \pm 0.03$ & $0.88 \pm 0.04$ \\
\hline $\mathrm{C} 3$ & 0.02 & 0.73 & -0.30 & 0.08 & -0.08 & -0.32 & 033 & 0.88 & 0.80 & $0.50 \pm 0.09$ & $0.97 \pm 0.01$ & $0.98 \pm 0.009$ \\
\hline $\mathrm{C} 4$ & -0.03 & 0.74 & -0.31 & -0.08 & -0.13 & -0.37 & -0.31 & 0.93 & 0.75 & 0.92 & $0.55 \pm 0.10$ & $0.98 \pm 0.004$ \\
\hline C4bis & -0.01 & 0.70 & -0.28 & -0.04 & -0.18 & -0.3 & -0.39 & 0.90 & 0.75 & 0.91 & 0.97 & $0.50 \pm 0.09$ \\
\hline
\end{tabular}


Table 6.

Expected genetic gain (in percent body weight units)for a generation of selection based on Massal (MS), Full Sib (FS), and Indirect (IS) selection for fillet and carcass yield, with different selection intensities (\% selected ).

\begin{tabular}{|c|c|c|c|c|}
\hline \multirow[t]{2}{*}{ Trait selected } & \multirow[t]{2}{*}{$\begin{array}{c}\text { Type of } \\
\text { selection }\end{array}$} & \multirow[t]{2}{*}{$\begin{array}{l}\text { Selection } \\
\text { intensity }\end{array}$} & \multicolumn{2}{|c|}{$\begin{array}{c}\text { Genetic gain } \\
\text { per generation }\end{array}$} \\
\hline & & & Fil\% & Carc\% \\
\hline $\mathrm{F} 1$ & IS & $10 \%$ & $0.25 \%$ & $-0.43 \%$ \\
\hline $\mathrm{F} 2$ & IS & $10 \%$ & $0.10 \%$ & $-0.17 \%$ \\
\hline F3 & IS & $10 \%$ & $0.36 \%$ & $0.21 \%$ \\
\hline F4 & IS & $10 \%$ & $0.34 \%$ & $-0.66 \%$ \\
\hline F4bis & IS & $10 \%$ & $0.09 \%$ & $-0.75 \%$ \\
\hline $\mathrm{C} 1$ & IS & $10 \%$ & $0.03 \%$ & $1.56 \%$ \\
\hline $\mathrm{C} 2$ & IS & $10 \%$ & $0.19 \%$ & $1.18 \%$ \\
\hline $\mathrm{C} 3$ & IS & $10 \%$ & $0.12 \%$ & $1.52 \%$ \\
\hline $\mathrm{C} 4$ & IS & $10 \%$ & $0.13 \%$ & $1.58 \%$ \\
\hline C4bis & IS & $10 \%$ & $0.20 \%$ & $1.51 \%$ \\
\hline R_Echo23 & IS & $10 \%$ & $0.16 \%$ & $1.17 \%$ \\
\hline Prop_head & IS & $10 \%$ & $0.14 \%$ & $1.22 \%$ \\
\hline Logr_Fil & MS & $10 \%$ & $0.57 \%$ & $0.29 \%$ \\
\hline Logr_Fil & MS & $30 \%$ & $0.38 \%$ & $0.19 \%$ \\
\hline Logr_Carc & MS & $10 \%$ & $0.19 \%$ & $1.71 \%$ \\
\hline Logr_Carc & MS & $30 \%$ & $0.12 \%$ & $1.13 \%$ \\
\hline Logr_Fil & FS & $10 \%$ & $0.65 \%$ & $0.33 \%$ \\
\hline Logr_Fil & FS & $30 \%$ & $0.43 \%$ & $0.22 \%$ \\
\hline Logr_Carc & FS & $10 \%$ & $0.16 \%$ & $1.43 \%$ \\
\hline Logr_Carc & FS & $30 \%$ & $0.10 \%$ & $0.95 \%$ \\
\hline
\end{tabular}


Figure captions

Fig. 2. Scheme of the different ultrasound measurements. Echo1: anterior-dorsal; Echo2: intermediate-dorsal; Echo3: posterior-dorsal; Echo4: anterior-lateral; Echo5: intermediate-lateral; Echo6: posterior-lateral; Echo7: anterior-ventral; Echo8: intermediate-ventral; Echo9: posteriorventral; Echo23: depth of the body cavity.

Fig. 1 Landmarks (bold) and semi-landmarks (italics) placed on each sea bass picture. 1: head extremity, 2: top of the eye; 3: bottom of the eye; 4: top end of the head and beginning of the dorsal fillet; 5: intersection of lateral line and head; 6: operculum posterior extremity; 7: anterior top extremity of pectoral fin; 8: anterior bottom extremity of pectoral fin; 9: posterior extremity of pectoral fin; 10: pelvic fin insertion; 11: bottom end of the head and beginning of the ventral fillet; 12: jaw extremity; 13: beginning of the first dorsal fin; 14: intersection of the lateral line with the vertical of point $13 ; 15$ : intersection of the ventral wall with the vertical of point 13 ; 16: end of the first dorsal fin; 17: intersection of the lateral line with the vertical of point 16; 18: intersection of the ventral wall with the vertical of point $16 ; 19$ : beginning of the second dorsal fin; 20: intersection of the lateral line with the vertical of point $19 ; 21$ : intersection of the ventral wall with the vertical of point 19; 22: beginning of the anal fin; 23: end of the second dorsal fin; 24: intersection of the lateral line with the vertical of point $23 ; 25$ : intersection of the ventral wall with the vertical of point 23; 26: end of the anal fin; 27: top of the caudal peduncle; 28 : intersection of the lateral line with the vertical of point $27 ; 29$ : intersection of the ventral wall with the vertical of point 27 ; 30: fork of the caudal fin.

Fig. 3: a) subdivision of the fish in 28 triangles b) triangles grouped in 12 representative surfaces. Apart from tail and head, all surfaces are separated between a dorsal part (S_XD) and a ventral part (S_XV) separated by the lateral line. 
Fig. 1

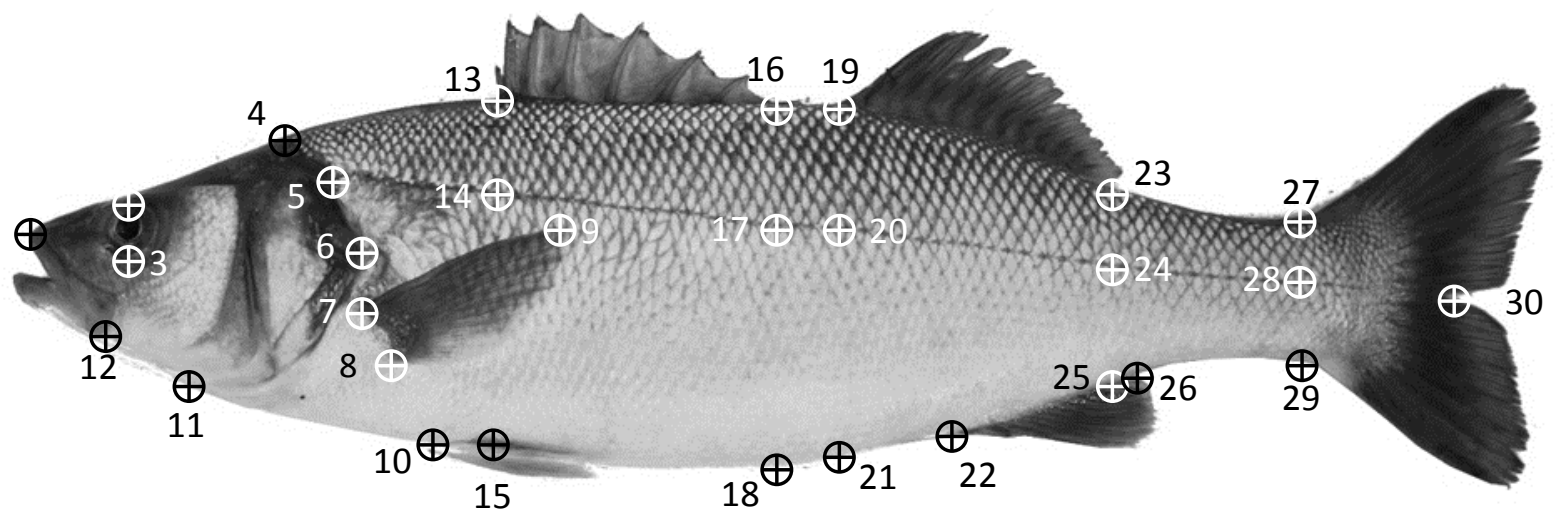

Fig. 2

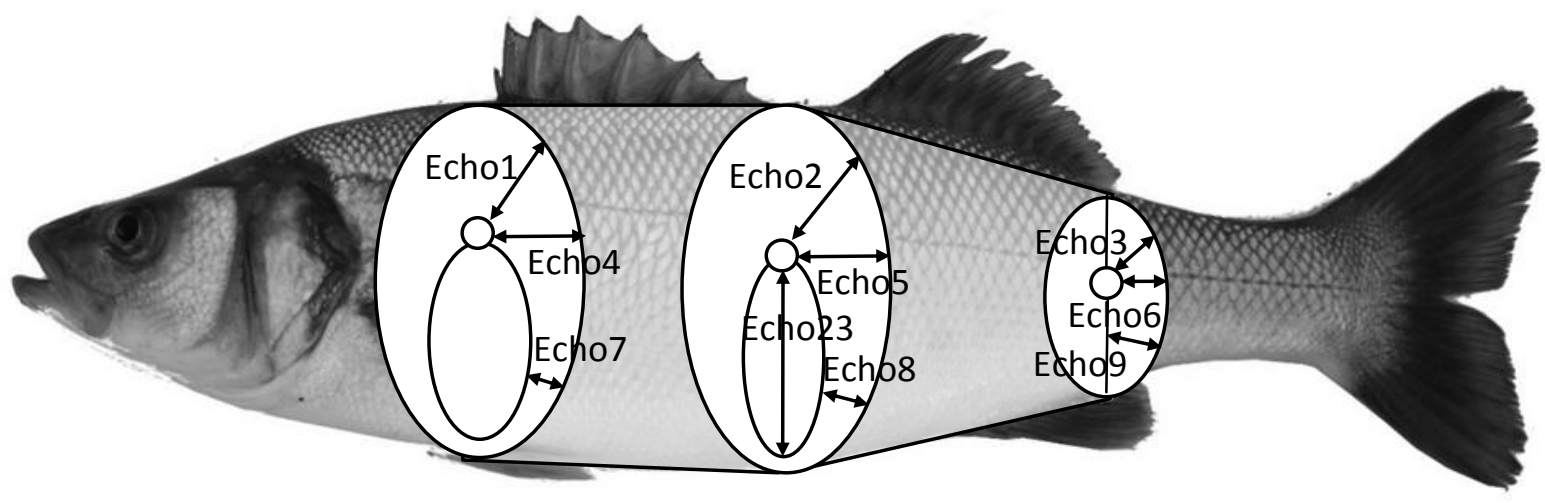


Fig. 3

a)

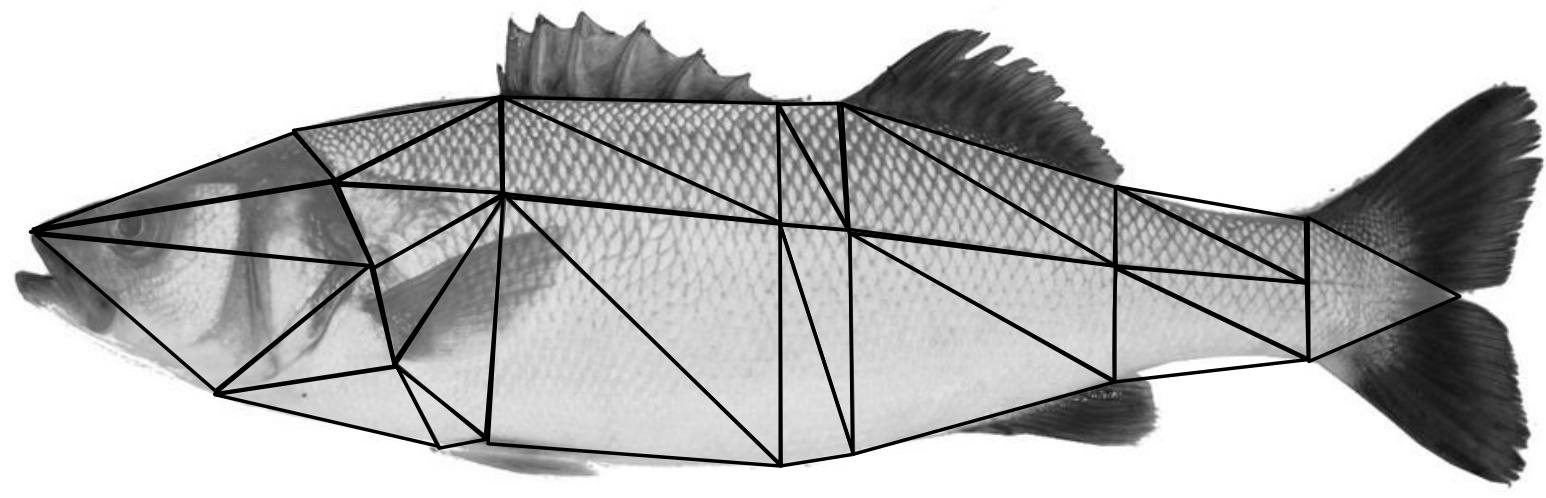

b)

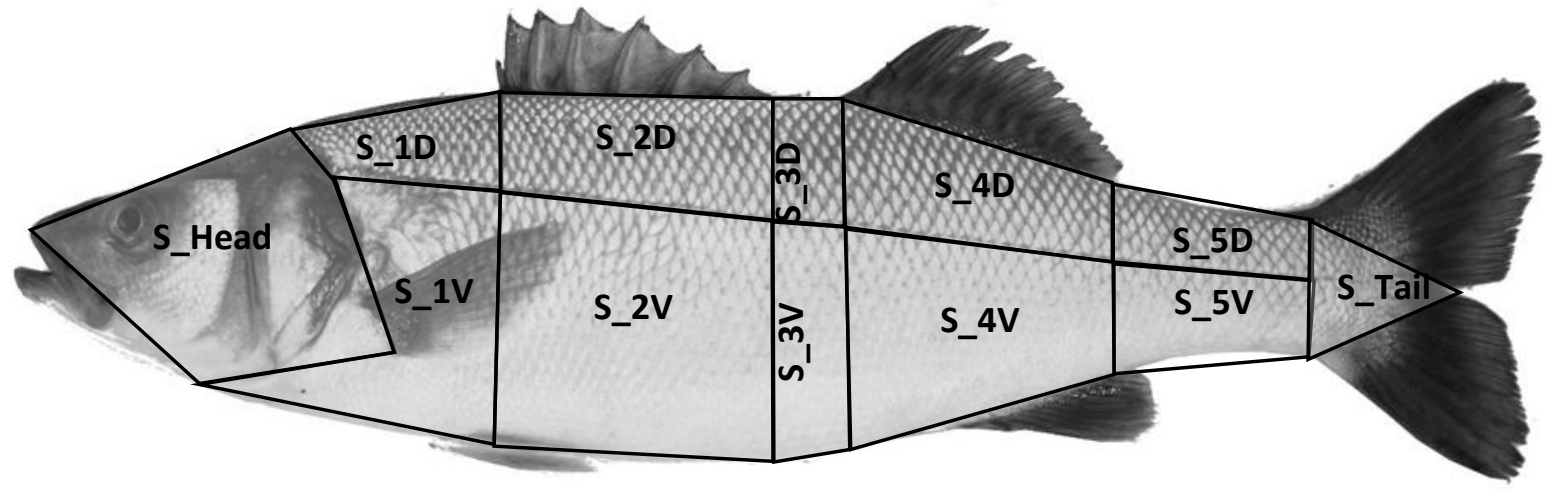




\section{REFERENCES}

Acosta-Alba, I., Aubin, J., Cariou, S., Haffray, P., Quittet, B., Vandeputte, M., 2015. Le programme FilD'or: associer sélection génétique et analyse d'impact environnemental des élevages de poissons. Courr. Envir. INRA 65, 49-57.

Bardon, A., Vandeputte, M., Dupont-Nivet, M., Chavanne, H., Haffray, P., Vergnet, A., Chatain, B., 2009. What is the heritable component of spinal deformities in the European sea bass (Dicentrarchus labrax)? Aquaculture 294, 194-201. doi:10.1016/j.aquaculture.2009.06.018.

Bestin, A., Dupont-Nivet, M., Haffray, P., Médale, F., Quillet, E., Vandeputte, M., Cariou, S., Desgranges, A., Laureau, S., Ricoux, R., Beutin, C., 2014. Genotype by diet interactions on growth and processing traits in rainbow trout (Oncorhynchus mykiss), European sea bass (Dicentrarchus labrax), gilthead sea bream (Sparus aurata) and meagre (Argyrosomus regius) fed diets with almost complete substitution of both fish meal and fish oil by vegetal ingredients. Proc.10th WCGALP, Vancouver, Canada.

Bisault, L., 2009. La salmoniculture française à l'étiage. Agreste Primeur 227. Ministère de l'Agriculture et de la Pêche, Montreuil-sous-bois, France

Bosworth, B. G., Holland, M., Brazil, B. L., 2001. Evaluation of ultrasound imagery and body shape to predict carcass and fillet yield in farm-raised catfish. J Anim. Sci. 79, 1483-1490.

Chatain, B., Chavanne, H., 2009. Genetics of European sea bass (Dicentrarchus labrax L.). Cah. Agricult. 18, 249-255. doi:10.1684/agr.2009.0296.

Chavanne, H., Janssen, K., Hofherr, J., Contini, F., Haffray, P., Komen, H., Nielsen, E.E., Bargelloni, L., 2016. A comprehensive survey on selective breeding programs and seed market in the European aquaculture fish industry. Aquacult. Int. 24, 1287-1307. doi:10.1007/s10499016-9985-0

Dupont-Nivet, M., Vandeputte, M., Vergnet, A., Merdy, O., Haffray, P., Chavanne, H., Chatain, B., 2008. Heritabilities and GxE interactions for growth in the European sea bass (Dicentrarchus labrax L.) using a marker-based pedigree. Aquaculture 275, 81-87 doi:10.1016/j.aquaculture.2007.12.032.

Dupont-Nivet, M., Karahan-Nomm, B., Vergnet, A., Merdy, O., Haffray, P., Chavanne, H., Chatain, B., Vandeputte, M., 2010. Genotype by environment interactions for growth in European seabass (Dicentrarchus labrax) are large when growth rate rather than weight is considered, Aquaculture. doi:10.1016/j.aquaculture.2010.05.025.

Falconer, D.S., MacKay, T.F.C., 1996. Introduction to Quantitative Genetics, 4th ed. Longman Scientific \& Technical, Harlow, UK.

FAO, 2016. Fisheries and aquaculture software. FishStatJ - software for fishery statistical time series. FAO Fisheries and Aquaculture Department [online]. Rome. Updated 21 July 2016.

García-Celdrán, M., Ramis, G., Manchado, M., Estévez, A., Afonso, J.M., Armero, E., 2015. Estimates of heritabilities and genetic correlations of carcass quality traits in a reared gilthead 
sea bream (Sparus aurata L.) population sourced from three broodstocks along the Spanish coasts. Aquaculture 446, 175-180. doi:10.1016/j.aquaculture.2015.04.028.

Gorshkov, S., Gorshkova, G., Meiri, I., Gordin, H., 2004. Culture performance of different strains and crosses of the European sea bass (Dicentrarchus labrax) reared under controlled conditions at Eilat, Israel. J. Appl. Ichthyol. 20, 194-203. doi:10.1111/j.14390426.2004.00513.x.

Gunsett, F.C., 1987. Merit of utilizing the heritability of a ratio to predict the genetic change of a ratio. J. Anim. Sci. 65, 936-942.

Golik, W., Dameron, O., Bugeon, J., Fatet, A., Hue, I., Hurtaud, C., Reichstadt, M., MeunierSalaun, M.C., Vernet, J., Joret, L., Papazian, F., Nédellec, C., Le Bail, P.Y., 2012. ATOL: the multi-species livestock trait ontology, in: 6th International Conference on Metadata and Semantic Research (MTSR'12). Cadiz, Spain.

Groeneveld, E., Kovač, M., Mielenz., N., 2008. VCE - User's Guide and Reference Manual Version 6.0. Institute of Farm Animal Genetics, Neustadt, Germany.

Haffray P., Pincent C., Dupont-Nivet, M., Vandeputte, M., Merdy, O., Chavanne, H., Chatain, B., 2007. Heritabilities and $\mathrm{G} \times \mathrm{E}$ interactions for quality traits in the European sea bass (Dicentrarchus labrax L.). Aquaculture, 272, S265. doi:10.1016/j.aquaculture.2007.07.080.

Haffray, P., Bugeon, J., Pincent, C., Chapuis, H., Mazeiraud, E., Rossignol, M.-N., Chatain, B., Vandeputte, M., Dupont-Nivet, M., 2012. Negative genetic correlations between production traits and head or bony tissues in large all-female rainbow trout (Oncorhynchus mykiss). Aquaculture 368-369, 145-152. doi:10.1016/j.aquaculture.2012.09.023.

Haffray, P., Bugeon, J., Rivard, Q., Quittet, B., Puyo, S., Allamelou, J.M., Vandeputte, M., DupontNivet, M., 2013. Genetic parameters of in-vivo prediction of carcass, head and fillet yields by internal ultrasound and 2D external imagery in large rainbow trout (Oncorhynchus mykiss). Aquaculture 410-411, 236-244. doi:10.1016/j.aquaculture.2013.06.016.

Karahan, B., Chatain, B., Chavanne, H., Vergnet, A., Bardon, A., Haffray, P., Dupont-Nivet, M., Vandeputte, M., 2013. Heritabilities and correlations of deformities and growth-related traits in the European sea bass ( Dicentrarchus labrax , L) in four different sites. Aquacult. Res. 44, 289-299. doi:10.1111/j.1365-2109.2011.03082.x.

Kause, A., Paananen, T., Ritola, O., Koskinen, H., 2007. Direct and indirect selection of visceral lipid weight, fillet weight, and fillet percentage in a rainbow trout breeding program. J. Anim. Sci. 85, 3218-3227.

Kocour, M., Mauger, S., Rodina, M., Gela, D., Linhart, O., Vandeputte, M., 2007. Heritability estimates for processing and quality traits in common carp (Cyprinus carpio L.) using a molecular pedigree. Aquaculture 270, 43-50. doi: 10.1016/j.aquaculture.2007.03.001

Le Bail, P.Y., Bugeon, J., Dameron, O., Fatet, A., Golik, W., Hocquette, J.F., Hurtaud, C., Hue, I., Jondreville, C., Joret, L., Meunier-Salaün, M.C., Vernet, J., Nedellec, C., Reichstadt, M., Chemineau, P., 2014. Un langage de référence pour le phénotypage des animaux d'élevage: L’ontologie ATOL. Prod. Anim. 27, 195-208. 
Navarro, A., Zamorano, M.J., Hildebrandt, S., Ginés, R., Aguilera, C., Afonso, J.M., 2009. Estimates of heritabilities and genetic correlations for growth and carcass traits in gilthead seabream (Sparus auratus L.), under industrial conditions. Aquaculture 289, 225-230. doi: 10.1016/j.aquaculture.2008.12.024

Neira, R., Lhorente, J.P., Araneda, C., Díaz, N., Bustos, E., Alert, A., 2004. Studies on carcass quality traits in two populations of Coho salmon (Oncorhynchus kisutch): phenotypic and genetic parameters. Aquaculture 241, 117-131. doi:10.1016/j.aquaculture.2004.08.009.

Perazza, C. A., Pinaffi, F. L. V., Silva, L. A., Hilsdorf, A. W. S., 2015. Evaluation of ultrasound imaging to predict loin eye area in tambaqui. Bol. Inst. Pesca, São Paulo, 41, $803-809$.

Rutten, M. J. M., Bovenhuis, H., Komen, H., 2004. Modeling fillet traits based on body measurements in three Nile tilapia strains (Oreochromis niloticus L.). Aquaculture 231, 113122. doi: 10.1016/j.aquaculture.2003.11.002

Rutten, M.J.M., Bovenhuis, H., Komen, H., 2005. Genetic parameters for fillet traits and body measurements in Nile tilapia (Oreochromis niloticus L.). Aquaculture 246, 125-132. doi : $10.1016 / \mathrm{j}$.aquaculture.2005.01.006

Saillant, E., Fostier, A., Haffray, P., Menu, B., Thimonier, J., Chatain, B., 2002. Temperature effects and genotype-temperature interactions on sex determination in the European sea bass (Dicentrarchus labrax L.). J. Exp. Zool. 292, 494-505. doi:10.1002/jez.10071.

Saillant, E., Dupont-Nivet, M., Haffray, P., Chatain, B., 2006. Estimates of heritability and genotype-environment interactions for body weight in sea bass (Dicentrarchus labrax L.) raised under communal rearing conditions. Aquaculture 254, 139-147. doi:10.1016/j.aquaculture.2005.10.018.

Saillant, E., Dupont-Nivet, M., Sabourault, M., Haffray, P., Laureau, S., Vidal, M.-O., Chatain, B., 2009. Genetic variation for carcass quality traits in cultured sea bass (Dicentrarchus labrax). Aquat. Living Resour. 22, 105-112. doi:10.1051/alr/2009010.

Sang, N. Van, Thomassen, M., Klemetsdal, G., Gjøen, H.M., 2009. Prediction of fillet weight, fillet yield, and fillet fat for live river catfish (Pangasianodon hypophthalmus). Aquaculture 288, 166-171. doi:10.1016/j.aquaculture.2008.11.030.

Vandeputte, M., Mauger, S., Dupont-Nivet, M., 2006. An evaluation of allowing for mismatches as a way to manage genotyping errors in parentage assignment by exclusion. Molecular Ecology Notes 6, 265-267. doi:10.1111/j.1471-8286.2005.01167.x.

Vandeputte, M., Dupont-Nivet, M., Chavanne, H., Chatain, B., 2007. A polygenic hypothesis for sex determination in the European sea bass Dicentrarchus labrax. Genetics 176, 1049-1057. doi : 10.1534/genetics.107.072140

Vandeputte, M., Dupont-Nivet, M., Haffray, P., Chavanne, H., Cenadelli, S., Parati, K., Vidal, M.O., Vergnet, A., Chatain, B., 2009. Response to domestication and selection for growth in the European sea bass (Dicentrarchus labrax) in separate and mixed tanks. Aquaculture 286, 20 27. doi:10.1016/j.aquaculture.2008.09.008. 
Vandeputte, M., Garouste, R., Dupont-Nivet, M., Haffray, P., Vergnet, A., Chavanne, H., Laureau, S., Ron, T.B., Pagelson, G., Mazorra, C., Ricoux, R., Marques, P., Gameiro, M., Chatain, B., 2014. Multi-site evaluation of the rearing performances of 5 wild populations of European sea bass (Dicentrarchus labrax).

Aquaculture

424-425, 239-248.

doi:10.1016/j.aquaculture.2014.01.005. 